\title{
VENDAS DE BEBIDAS ALCOÓLICAS: QUESTÕES (IM)PERTINENTES
}

\author{
Mirian Cátia Vieira Basílio \\ Maria Lúcia Teixeira Garcia \\ Universidade Federal do Espírito Santo
}

\begin{abstract}
RESUMO: O objetivo deste estudo é analisar a disponibilidade e o acesso à bebida alcoólica num bairro da cidade de Vitória/ES. Os dados foram obtidos através de pesquisa de campo na região selecionada utilizando a observação simples e a entrevista através da aplicação de questionários numa amostra de $10 \%$ dos estabelecimentos encontrados. Os pontos de venda funcionam 7 dias por semana; $68,8 \%$ vendem a credito e a um preço médio de $\mathrm{R} \$ 0,41$ (a dose de cachaça). 93,8\% dos entrevistados não solicitam documento de identidade ao cliente antes de lhe vender bebidas. A relação entre número de moradias e número de pontos de venda foi de 3:1. A alta concentração de estabelecimentos que vendem bebidas alcoólicas no bairro aponta para a necessidade de pensar o entorno (regiões vizinhas) da mesma. Estas regiões envolvem áreas marginalizadas onde ocorre tráfico de drogas, fazendo da região estudada uma área importante para o comércio, pela facilidade de acesso aos outros bairros adjacentes da cidade.
\end{abstract}

PALAVRAS-CHAVE: política do álcool; violência; saúde pública.

\section{SELLING ALCOHOLIC BEVERAGES: (IM)PERTINENT QUESTIONS}

\begin{abstract}
The objective of this study is to analyse the availability and access to alcoholic beverages in a neighbourhood in the city of Vitória/ES. Data was obtained by means of field research using simple observation method and the application of questionnaires in a sample of $10 \%$ of the establishments encountered in the region. These establishments are open seven days a week; $68,8 \%$ of these markets sell on credit and at a medium price of $\mathrm{R} \$ 0,41$ (one dose of "cachaça"). 93,8\% of the sellers who were interviewed doesn't check the identity cards of their clients before selling them the alcoholic beverages. The relation between the number of houses and establishments was 3:1. The high concentration of establishments which sell alcoholic beverages in the neighbourhood brings up the necessity to think about the neighbouring regions. These regions include marginalized areas where there is drug trafficking, making the studied region an important commercial area because of its easy access to other neighbouring regions in the city.
\end{abstract}

KEYWORDS: alcohol policies; violence; public health.

Uma política pública é resultado de um longo e emaranhado processo que envolve interesses divergentes, confrontos e negociações entre várias instâncias e atores. É definida pelo resultado das relações e mobilizações estabelecidas entre esses atores; pelas instituições que podem facilitar ou impedir o acesso dos atores aos espaços decisórios; pelo processo de decisão, no qual se estabelecem coalizões e escolhas e também pelos produtos da política resultante (Silva, 2000). Independente das áreas em que atuam e/ou interferem, são tentativas de regular situações que apresentam problemas públicos, situações essas afloradas no interior de uma coletividade ou entre coletividades (Lemieux in Viana, 1996).

Uma política pública, via de regra, é mais que decisão e requer diversas ações estrategicamente selecionadas para implementar as decisões tomadas. Afinal, a decisão política corresponde a uma escolha a partir de várias alternativas, conforme a hierarquia das preferências dos atores envolvidos, expressando uma certa adequação entre os fins pretendidos e os meios disponíveis. Uma política pública implica decisão política, mas nem toda decisão política constitui uma política pública (Rua, s/d).

A dimensão pública de uma política é dada pelo seu caráter imperativo, ou seja, o fato de que são decisões e ações revestidas da autoridade do poder público. Na análise de uma política pública implementada por um governo, fatores de diferentes natureza e determinação são importantes. Estes diferentes aspectos devem referir-se a uma concepção de Estado na qual as políticas se movimentem, e requerer ainda a compreensão lógica das diferentes formas de intervenção sobre a sociedade, a fim de identificar os modos de relação existentes entre os atores públicos e privados e de compreender como a ação pública envolve dinâmicas pouco nítidas e evolutivas na fronteira entre Estado e sociedade.

As políticas que têm como objetivo a redução da carga de problemas com o álcool são necessárias e envolvem uma intrincada luta entre diferentes grupos de interesse para que sejam (ou não) adotadas medidas políticas que sirvam como estratégia global de criação de um ambiente 
que ajude as pessoas a fazerem escolhas saudáveis ${ }^{1}$ (Edwards, 1994).

\section{Políticas Públicas para o álcool}

As políticas públicas para o álcool hoje oscilam entre medidas de controle sobre o comportamento do consumidor de álcool e medidas de controle sobre o acesso à disponibilidade de bebidas alcoólicas. De acordo com as ações de intervenção preconizadas pela Organização Mundial de Saúde no ramo das políticas públicas, destacam-se (World Health Organization, 1995): a) aumento do preço do produto; b) proibição de propagandas na mídia; c) restrições de vendas em locais próximos a: escola, hospitais, etc; d) campanhas na mídia e nas escolas para maiores informações sobre os efeitos do álcool; e) política de restrição à prática de beber e dirigir.

\section{Políticas de Taxação do álcool}

Consideradas de impacto social imediato, as políticas de preço e de taxação têm sido a estratégia usada por governos de diferentes países para controlar os problemas relacionados ao consumo do álcool. Estudos têm mostrado que essa estratégia é eficaz, ao passo que o preço do álcool segue o padrão de qualquer mercadoria (United States, 2003). De acordo com dados de pesquisas, quanto maior o preço menor o consumo, pois mesmo os bebedores pesados diminuem o consumo de acordo com a alta (Edwards, 1994). Laranjeira (2004) sugere que este poderia ser um dos modelos de política aplicáveis ao Brasil, onde o preço do álcool é considerado um dos mais baixos do mundo ocidental, inclusive por se tratar de uma medida de baixo custo, de fácil aplicação (através da lei) e de fácil fiscalização.

No Brasil, o preço médio de uma dose de cachaça é $\mathrm{R} \$ 0,45$, uma cerveja em lata das marcas mais procuradas custa em média $\mathrm{R} \$ 0,99$, sendo que o custo de um litro de leite das marcas mais populares chega a custar $R \$ 1,40$, preço equivalente ao de um litro de cachaça. Caso comparemos o aporte calórico de cada um, o litro de cachaça possui, em média, $1540 \mathrm{Kcal}$, enquanto o de leite fornece $600 \mathrm{Kcal}$. Assim, frente à fome e à impossibilidade de acessar comida, a bebida alcoólica pode ser uma via de supressão momentânea da fome, mas não da superação da desnutrição, uma vez que a bebida alcoólica não possui vitaminas, proteínas ou sais minerais (Gomes, 1990). Sobretaxar a bebida alcoólica seria tratá-la como um produto diferenciado.

Analisando essa política, Babor ${ }^{2}$ aponta que possui uma alta efetividade e um baixo custo, atingindo à população geral. No entanto, medidas assim sofrem pressões de vários setores para a sua não-efetivação, seja por parte da indústria, seja por parte da população consumidora.

\section{Álcool e mídia}

A propaganda de bebidas alcoólicas no Brasil é regulada pela lei n. 9.294, de 1996. A principal restrição apre- sentada é a redução do horário de propaganda na televisão e no rádio, permitindo propagandas de álcool entre $21 \mathrm{~h}$ e $6 \mathrm{~h}$ horas. No entanto, as chamadas, propagandas de uns poucos segundos, são permitidas a qualquer horário. A partir de 2000, uma nova lei (n.10.167) foi sancionada e proibiu qualquer propaganda de cigarro (exceto dentro dos locais de venda). Apesar dessa proibição não atingir as bebidas alcoólicas, é crescente o movimento propositivo de medidas restritivas à propaganda de bebidas alcoólicas. A partir de 2002, mais de 50 projetos de lei foram propostos de restrições às propagandas de álcool.

Todas as noites nossas residências são invadidas por anúncios publicitários que associam a figura de jogadores de futebol (como Ronaldo) a marcas de bebida alcoólica, algo proibido pela legislação brasileira. A adoção desses mecanismos de propaganda acabam por levar ao público a falsa idéia de que as bebidas alcoólicas, principalmente no que concerne à cerveja, estão ligadas à diversão, ao sucesso profissional, à sexualidade e à saúde (Paschoal, 2005). Outro aspecto diz respeito à indústria de bebidas alcoólicas, que se constitui em um grupo de interesses organizado com efetiva ação na esfera governamental.

A mídia é considerada por muitos especialistas como um risco para a postura da população no sentido de estimular ao consumo de álcool, principalmente entre crianças e adolescentes, mas as tentativas de restrições às propaganda de bebidas alcoólicas têm sido contidas pela ação de lobby da indústria alcooleira. ${ }^{3} \mathrm{~A}$ introdução de novos produtos e a exposição na propaganda são consideradas a melhor estratégia de marketing adotada pela indústria de bebidas. A indústria de bebida alcoólica tem-se envolvido na arena política, em geral, para proteger seus interesses comerciais. Em alguns países a indústria tem presença dominante na área governamental, sendo visualizada na cadeira política. É comum a ação de representantes das indústrias influenciando outros atores sociais no momento da construção da agenda política, na escolha da legislação políticas e na escolha dos debates políticos (Babor, Caetano \& Casswell, 2003).

A política de regulação das propagandas é de grande relevância, tendo em vista que a propaganda do álcool visa a criar um clima social de tolerância e estímulo à bebida (Laranjeira \& Romano, 2003). Iniciado em maio de 2003, o encontro do grupo interministerial criado para definir uma política nacional de enfrentamento da problemática do alcoolismo formulou algumas linhas de ações. Foram propostas, entre outras, a restrição de propaganda de bebidas alcoólicas na televisão entre as $23 \mathrm{~h}$ e $6 \mathrm{~h}$. A proibição de propaganda nesse período foi julgada como a mais eficaz segundo os especialistas em prevenção e tratamento de problemas relacionados ao álcool (Brasil, 2003). Entretanto, após nove meses de trabalho do grupo interministerial, não houve acordo sobre os pontos cruciais do assunto, entre os quais: restrição de propaganda, aumento do preço 
do produto e limitação da venda (Leite, 2004). Sucessivos governos brasileiros têm cedido ao lobby dos produtores e deixado de tomar as medidas necessárias contra a publicidade do álcool. No Brasil, as restrições existentes são apenas direcionadas às propagandas de bebidas com teor alcoólico acima de $13^{\circ}$ Gay Lussac que sofrem restrições de horário. Já as bebidas como cervejas, vinhos e bebidas tipo "ice" podem veicular seus reclames em horário nobre e até infantil (Pinsky, 2004).

Pinsky (1994), ao analisar o conteúdo das propagandas veiculadas nos meios de comunicação nos anos de 1993 e 1994, observa que as propagandas de bebidas estavam associadas à sensação de relaxamento, humor e divertimento. As mensagens veiculadas em outdoors, na imprensa escrita e na televisiva enquadravam o ato de beber como algo prazeroso e que se fazia no âmbito de diferentes grupos sociais e em diferentes situações, fosse em momentos alegres ou tristes (Baioco, 1999). Além das propagandas, têm sido fabricadas uma série de "novas bebidas" voltadas para o público jovem. Tais bebidas são similares a refrigerantes alcoólicos à base de destilados (uísque, vodka etc.), atendendo ao gosto de um possível novo mercado consumidor.

A indústria do álcool, combinada com a prosperidade dos principais países industrializados, tem uma capacidade de influenciar a arena da política pública de forma significativa (Edwards, 1994). Em alguns países, uma grande quantidade de dinheiro é gasta com marketing, assim a estratégia da propaganda e da mídia é jogar no limite das restrições jurídicas, colocando os interesses da indústria à frente dos interesses das políticas do álcool, especialmente no que diz respeito às propostas das propagandas. Apesar de esses grupos investirem na promoção do uso do álcool, observa-se também sua presença no processo de propaganda política através de financiamento de campanhas de candidaturas a cargos no Legislativo.

No Brasil está em tramitação o projeto de lei $\mathrm{n}^{\circ} 35$ (2000), que propõe como definição de bebida alcoólica "líquido potável com qualquer teor alcoólico" e determina a obrigatoriedade de a embalagem, o rótulo e a propaganda de bebida alcoólica conterem advertência sobre a proibição de sua venda a menores de dezoito anos e sobre sua prejudicialidade à saúde. Ao propor alteração à lei 9.294, modifica-se o conceito de "bebida", transferindo as atuais propagandas da indústria cervejeira para o horário noturno. Tramitando desde 2000 no Congresso Nacional, esse projeto de lei ainda não foi aprovado. Analisandose esse período, observa-se que no Brasil os gastos com propagandas de cervejas vêm apresentando crescimento de quase $100 \%$ entre os anos de 2000 e 2004, e crescimento nas vendas da ordem de 13\% (Pinky, 2004). Ante um tal quadro, a Câmara Técnica de Políticas Públicas do Álcool (pertencente à estrutura do Conselho Nacional Antidrogas) propõe que seja efetivada mudança na lei que regu- lamenta a propaganda de bebidas alcoólicas. Um dos passos seria a atual consulta pública $\mathrm{n}^{\circ} 83$ (de novembro de 2005), realizada pela Agência de Vigilância Sanitária (ANVISA) de proposta de regulamento técnico sobre propaganda comercial de bebidas potáveis com teor alcoólico superior a treze graus Gay Lussac (ANVISA, 2005).

\section{Campanhas na mídia e nas escolas com informações sobre os efeitos do álcool}

Essas campanhas têm como objetivo informar melhor sobre os efeitos do álcool (Bertolote, 1997). Ao analisar a literatura internacional sobre propaganda, prevenção e representação das bebidas alcoólicas nos meios de comunicação, Pinsky (1994) conclui que as imagens do álcool na mídia parecem ter o efeito de cotidianizar, banalizar e legitimar o consumo de bebidas alcoólicas acabando, assim, por diluir a eficácia das campanhas de prevenção.

Programas de informações sobre os males do álcool nas escolas poderão surtir efeito se forem acompanhadas de outras políticas que não sejam contraditórias, já que de nada adiantaria o educador informar ao aluno sobre os prejuízos do álcool e de outras drogas, enquanto as propagandas continuam mostrando situações que incentivam o consumo e estimulando a percepção de que o álcool não faz mal (Edwards, 1994; Laranejria, 2004).

\section{Política de restrição à prática de beber e dirigir}

No que diz respeito aos acidentes de trânsito, o comportamento de dirigir alcoolizado (que tem como consequiência acidentes de trânsito) tem gerado discussões em nível internacional. Especificamente em relação ao Brasil, os dados epidemiológicos da ocorrência de acidentes de trânsito com relação ao uso de álcool são escassos: somente em 1997, com estudos colaborativos entre o RAID - Instituto Recife de Atenção Integral às Dependências e o ABDETRAN - Associação Brasileira dos Departamentos de Trânsito, foram constituídas informações relevantes sobre os efeitos de beber e dirigir no País. Estudiosos do RAID constataram que $23 \%$ dos entrevistados apresentavam alcoolemia de $0,8 \mathrm{~g} / \mathrm{l}$, tendo como resultado acidentes de trânsito relacionados à alta concentração de álcool no sangue, que ocorrem com mais freqüência durante a noite e aos fins de semana, tendo como autores em sua maioria, homens jovens e solteiros (Oliveira \& Melcop, 1997). No mesmo ano, foi realizado um estudo pelo ABDETRAN em quatro capitais brasileiras: Brasília, Curitiba, Recife e Salvador, em que das 865 vítimas, 27,2\% apresentaram alcoolemia superior a $0,6 \mathrm{~g} / \mathrm{l}$ (ABDETRAN, 1997).

Dentre os vários problemas relacionados ao uso abusivo de bebidas alcoólicas, dirigir alcoolizado, tendo como resultado o envolvimento em acidentes de trânsito, tem ocupado uma colocação proeminente (Pinsky, 1999). A ingestão de álcool, mesmo em pequenas quantidades, prin- 
cipalmente para os adolescentes, mais vulneráveis aos efeitos do álcool do que o bebedor pesado (Holder, 2001), diminui a coordenação motora e os reflexos, comprometendo a capacidade de dirigir veículos ou operar outras máquinas, podendo levar a situações mais graves que impliquem em ferimentos ou mortes não-intencionais (Romelsjo in Edwards, 1994). Por exemplo, um motorista adulto, com concentração de álcool entre 0,5 e 0,9 (dentro dos limites permitidos pelas leis) tem nove vezes maior risco de se envolver em acidente (Ross, in Pinsky, 1999). Iniciativas legislativas para aumentar a idade mínima de beber para 21 anos têm produzido significativo declínio em relatos de acidentes e mortes no trânsito (United States, 2003).

O estabelecimento de taxa máxima de álcool no sangue foi uma medida legalmente necessária a partir de estudos que investigaram o efeito de bebidas alcoólicas ao dirigir (Pinsky, 1999). Nesse sentido, segundo a legislação brasileira (Código Nacional de Trânsito) em vigor desde janeiro de 1998, será penalizado todo motorista que apresentar mais de 0,6 gramas de álcool por litro de sangue. A quantidade de álcool necessária para atingir essa concentração no sangue é equivalente à ingestão de cerca de $600 \mathrm{ml}$ de cerveja (duas latas de cerveja ou três copos de chope), $200 \mathrm{ml}$ de vinho (duas taças) ou $80 \mathrm{ml}$ de destilados (duas doses), segundo reporta Ceará (2003). Outras medidas restritivas têm sido adotadas, como a utilização do teste de bafômetro.

No Espírito Santo (Brasil), os projetos "Madrugada Viva", "Praia Viva"e "Montanha Viva", criados pelo Departamento Estadual de Trânsito (DETRAN/ES), em parceria com o Batalhão de Trânsito Rodoviário e Urbano da PMES - BPRv, Delegacia de Delito de Trânsito, Secretaria Municipal de Transportes e Infra-Estrutura da Prefeitura Municipal de Vitória (PMV) e Cooperativa Médica (UNIMED), vêm fazendo um trabalho no sentido de conscientizar e educar a população e os motoristas sobre os riscos de envolvimento em acidentes de trânsito relacionados com o consumo de bebidas alcoólicas (Espírito Santo, 2004). Dados estatísticos apontam que o maior número de casos de acidentes com veículos ocorrem aos finais de semana, tendo como maior número de vítimas pessoas com faixa etária entre 18 e 29 anos, correspondendo a cerca de $40 \%$ dos casos (Vitória, 2003). Os resultados mostram que entre o ano de 2004 e 2005 houve uma diminuição de acidentes com vítimas fatais. Estudos apontam que a adoção de ações de restrição à prática do beber e dirigir produz ao longo do tempo redução entre $5 \%$ a $30 \%$ de acidentes automobilísticos. A realização continuada de blitzes policiais com verificação de consumo alcoólico (através do teste do bafômetro de forma aleatória) contribui para a redução efetiva de acidentes e mortes no trânsito (Babor et al., 2003).

Ao se analisarem as questões relacionadas ao uso do álcool e as punições previstas no Brasil, chega-se à defi- nição de que essas não são brandas, pois o motorista que for abordado e cujo teste de bafômetro apontar consumo acima do permitido será multado em $\mathrm{R} \$ 951,00$, tendo ainda a penalização de sete pontos na carteira de habilitação, a retenção de seu veículo e uma possível suspensão da licença para dirigir por até um ano (Ceará, 2003). São raras, porém, as situações em que há condenações em caso de acidentes provocados por pessoas alcoolizadas, muitas vezes pela resistência ao teste do bafômetro, já que este não é obrigatório. Com isso, podemos notar que há uma descrença generalizada nas instâncias governamentais responsáveis pela segurança da população (Espírito Santo, 2003). Tais medidas restritivas só irão realmente funcionar se a população tiver conhecimento e atribuir legitimidade à penalidade que será aplicada (Edwards, 1994; Ross in Pinsky, 1999). Um estudo conduzido em São Paulo apontou que $74 \%$ dos indivíduos jovens entrevistados achavam que ninguém ou apenas poucas pessoas condenadas por dirigir alcoolizadas realmente recebiam a punição exigida por Lei (Pinsky, 1999).

A preocupação hoje em vários países é com o grupo de jovens (entre 16 e 20 anos), considerados grupo de risco de envolvimento em acidentes automobilísticos após ingestão alcoólica.

\section{Restrições de vendas em locais próximos a escola, hospitais, etc}

Um estudo realizado por Laranjeira (2004) aponta que quanto menor o número de locais vendendo o álcool, maior o respeito ao limite de idade para a venda de bebidas alcoólicas, maior a consistência de leis do beber e dirigir, menor o consumo global da população. A redução na oferta leva a aumentos de custos do álcool e consequiente redução nas vendas. Com isso, a disponibilidade física tem o potencial de influenciar a demanda do consumidor pelas bebidas alcoólicas (Chaloupka, Grossman \& Saffer, 2002). Quanto menor a densidade, maior a oportunidade de lucro na venda de álcool, o que tende a elevar seu preço e, conseqüentemente, diminuir o consumo e os problemas relacionados. As medidas sugeridas nesse caso são de adoção de leis de zoneamento e planejamento urbanos que poderão ser usados para regular a densidade dos pontos de venda, e restringir a sua localização (Chaloupka et al., 2002).

Como qualquer produto comercial, o álcool torna-se disponível aos consumidores através dos pontos de venda. Entretanto, tais pontos de venda podem ser licenciados (como bares, restaurantes etc.) ou não (casas, estabelecimentos clandestinos, vendedores ambulantes etc.). Os estabelecimentos podem ter licença para a venda de álcool a ser consumido no próprio estabelecimento (bares, restaurantes) ou fora dali (supermercados, lojas de conveniência, distribuidoras de bebidas etc.). A relação entre a quantidade e os tipos de estabelecimentos autorizados à comer- 
cializar bebidas alcoólicas em uma comunidade sofrem diferentes influências, tais como: o tamanho da população, consumo per capita e fatores econômicos (Holder, 1997).

Em um estudo realizado no Jardim Ângela, uma região densamente povoada da cidade de São Paulo, onde existem altos níveis de privação social e de violência, Laranjeira, e Hiskly (2002) encontraram a mais alta densidade de pontos de venda de álcool relatada na literatura (a cada 12 moradias, 1 propriedade que vendia álcool).

O objetivo deste trabalho é analisar a disponibilidade e o acesso à bebida num bairro de Vitória/ES.

\section{Método}

Foi solicitada à Secretaria de Desenvolvimento da Cidade (SEDEC) e ao Sindicato dos Bares (SINDIBARES) uma listagem contendo nomes e localização de pontos que comercializam bebidas alcoólicas em todo o município de Vitória. Em uma primeira análise das duas listas, observou-se uma alta concentração de pontos de vendas de bebidas (para cada 4 moradias 1 bar) num bairro localizado na região central de Vitória. Com esses dados, optouse por desenvolver um estudo no local.

Inicialmente foi realizada visita à comunidade com o apoio de um mapa em que eram registrados os pontos de venda de bebidas alcoólicas e ainda anotadas observações em um diário de campo. Na comunidade foi observado: a) número e tipo de estabelecimento que comercializa bebida alcoólica; b) localização e distância de escolas e creches; c) tempo de funcionamento; d) relação entre número de bares e similares; e) concentração populacional da comunidade.

Na visita ao bairro foram identificados 173 pontos de venda de bebidas alcoólicas. Destes, foi definida uma amostra não-probabilística do tipo intencional ${ }^{4}$ que englobou 8 pontos fixos e 8 pontos móveis.

- pontos fixos: 4 estabelecimentos nos quais o objetivo principal era a venda de bebidas alcoólicas (sendo 2 localizados em região comercial e 2 localizados em região residencial) e 4 nos quais o objetivo principal do comércio não era a venda de bebidas alcoólicas (sendo 2 localizados em região comercial e 2 localizados em região residencial);

- pontos móveis: 4 estabelecimentos nos quais o objetivo principal era a venda de bebidas alcoólicas (sendo 2 localizados em região comercial e 2 localizados em região residencial) e 4 onde o objetivo principal não era a venda de bebidas alcoólicas (sendo 2 localizados em região comercial e 2 localizados em região residencial).

Foi utilizado um formulário desenvolvido por Laranjeira e Hinskly (2002), ${ }^{5}$ no qual se levantaram: razões para abertura do estabelecimento; empregados; quantidade e tipo de bebida comercializada; preço do produto; horário de funcionamento; tipo de consumidores/freqüentadores de seu estabelecimento, atitude de pedir documento de identidade antes da venda, atitudes e opiniões sobre a venda de bebidas alcoólicas, entre outras.

Como procedimento ético, foi solicitado aos entrevistados que assinassem o termo de consentimento livre e esclarecido, no qual autorizaram sua participação no estudo e concordaram com o uso de informações para uso na pesquisa. No entanto, foram suprimidos os dados de identificação dos entrevistados, como forma de assegurar $\mathrm{o}$ anonimato destes.

\section{Resultados}

Foram percorridos um total de 21 ruas (oficiais e nãooficiais) e 3 avenidas distribuídas numa área de $150.476 \mathrm{~m}^{2}$ que corresponde ao tamanho do bairro. Foi obtido um total de 173 estabelecimentos que vendem bebidas alcoólicas, dentre os quais 150 pontos fixos e 23 pontos móveis. A proporção entre pontos de venda de bebidas alcoólicas e o número de moradias (449 no total) foi de 1:2,6.

A Figura 1 apresenta um mapa com a localização dos pontos de vendas de bebidas alcoólicas no bairro, podendose visualizar uma alta concentração de estabelecimentos que vendem bebidas alcoólicas. Dos 173 pontos de venda, 50,3\% são bares (bar, bar/restaurante, bar/lanchonete).

A concentração dos pontos de vendas de bebidas alcoólicas localiza-se entre as vias consideradas de melhor fluxo ao bairro. Há uma maior concentração destes estabelecimentos em uma avenida e uma rua, ambas situadas na região comercial. Na região residencial há uma prevalência de estabelecimentos que comercializam bebidas alcoólicas em uma rua principal, que cruza o bairro. Nessa região, estão localizadas uma pré-escola e uma unidade de saúde, situadas nas proximidades dos pontos de venda de bebidas alcoólicas.

Os comerciantes, em geral, residem no próprio bairro. Dos 16 entrevistados, 12 relataram abrir o estabelecimento 7 dias na semana, tendo uma permanência de abertura média de 83,3 horas por semana (ou seja, em média 12 horas por dia). Metade dos estabelecimentos mantém-se aberta no período dia e noite; sete (7) funcionam apenas no período diurno e um funciona apenas no período noturno. Um dado relevante é que não houve citação de limite comercializado no estabelecimento em $100 \%$ das entrevistas. Foram encontradas variações de preço entre $\mathrm{R} \$ 1,70$ e $\mathrm{R} \$ 2,50$, para a cerveja em garrafa $(600 \mathrm{ml})$. De acordo com os comerciantes, a bebida mais vendida é a cachaça, tendo um valor de venda médio de $\mathrm{R} \$ 0,41$ por dose de $50 \mathrm{ml}$. A variação de preço encontrada por essa bebida foi de $\mathrm{R} \$ 0,25$ a 0,41 (Tabela 1 ). 


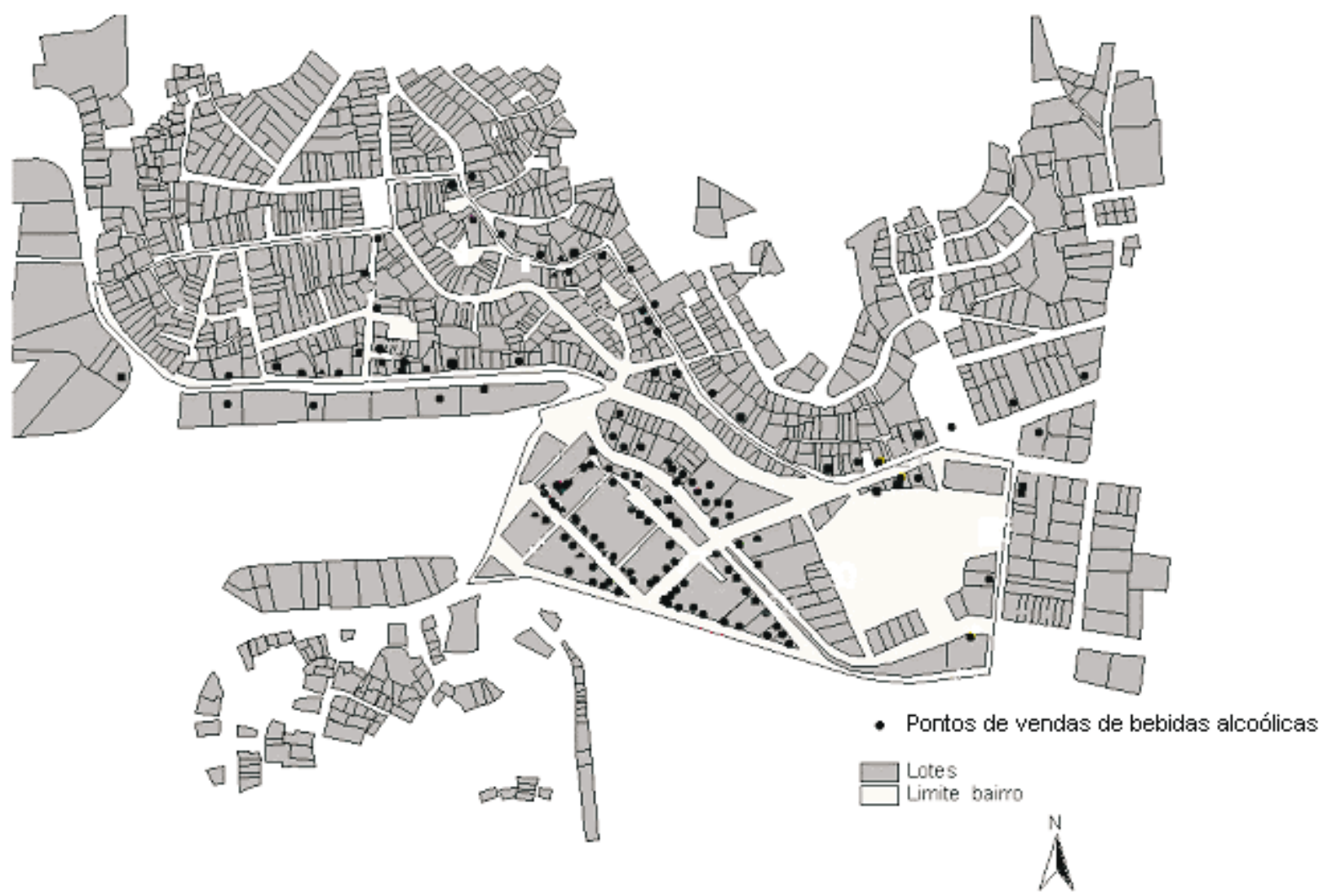

Figura 1. Mapa da concentração espacial dos pontos de venda de bebidas alcoólicas.

Tabela 1. Síntese dos Dados Levantados.

\begin{tabular}{lr}
\hline População & 1.437 \\
\hline Área/m² & 150.476 \\
\hline № de moradias & 449 \\
\hline № pontos de vendas & 173 \\
\hline Relação Moradias: pontos de venda & $2,6: 1$ \\
\hline Média de freqüentadores nos pontos de venda & 50 \\
\hline Média de preço da cerveja/R $\$$ & 2,04 \\
\hline Média de preço da cachaça/R\$ & 0,33 \\
\hline Média de dias de abertura & 6,8 \\
\hline Média de horas de abertura & 12 \\
\hline Solicitação de documentação a menores de 18 anos & Sim (\%) \\
\hline
\end{tabular}

Ao serem perguntados sobre a iniciativa de solicitar um documento de identidade ao cliente antes de lhe vender bebida, 11 responderam não fazer esta solicitação. Avaliando se seus funcionários (ou de qualquer estabelecimento) fazem o suficiente para evitar vender bebidas a menores de 18 anos, 11 entrevistados responderam que não, sendo que destes, 7 foram os mesmos que responde- ram não solicitar um documento de identidade ao cliente antes de lhe vender bebida.

Em termos de implicações legais quanto ao fato de reconhecerem que havia uma inobservância ao previsto em lei (comercialização de bebidas a menores de idade), metade dos entrevistados discorda quanto à responsabilidade do estabelecimento em caso de intoxicação por bebida do 
cliente no local. No entanto, 11 concordam quanto ao dever do estabelecimento de evitar que um cliente embriagado dirija.

De acordo com informações fornecidas pelo Departamento da Polícia Militar do bairro, mais de $90 \%$ das ocorrências atendidas estão relacionadas com o abuso do álcool, como por exemplo brigas dentro de bares entre bebedores alcoolizados e dano material para proprietário causado pelo bebedor alcoolizado. Entretanto, a maior parte destas ocorrências não é registrada, mas resolvida no próprio local pela Polícia Militar (Vitória, 2004).

Também foram relatadas a existência do comércio de drogas ilícitas (principalmente de crack e cocaína) e a prostituição que acontecem no bairro, principalmente no período noturno. O mercado da prostituição é mantido por pessoas provenientes de outros bairros, municípios e até mesmo de outros estados e países devido à proximidade do bairro com a região portuária. A circulação dos diversos atores no cenário faz com que os estabelecimentos localizados nesta região permaneçam um maior número de dias e horas abertos.

O não cumprimento da legislação que regulamenta a comercialização de bebidas alcoólicas a menores de 18 anos é mais um dado que se junta a esse quadro. De acordo com essa lógica, o cenário que se vislumbra é o da bebida como um produto como qualquer outro e cujo consumo deve ser regulado pelas regras de compra e venda, ou seja, em havendo consumidores há sempre disponibilidade para se fazer o "negócio". Este negócio - venda e consumo de bebidas alcoólicas - ocorre em um bairro marcado por múltiplas dinâmicas que se distinguem: de dia - circulação de famílias trabalhadoras, de consumidores de produtos populares (no Mercado Popular), de viajantes (próximo ao porto e à rodoviária), de usuários de unidades básicas de saúde; de noite - um bairro típico da boemia, do tráfico de drogas e da prostituição e também um espaço de famílias pobres que residem no local sem qualquer relação com o tráfico ou com a prostituição.

\section{Discussão}

Vemos que a ampla variação de locais que vendem bebidas, no caso deste bairro, acaba levando a naturalização de qualquer local como espaço para beber. No bairro a venda ocorre nos bares e restaurantes, mas também nas ruas (no carrinho de churrasco, na barraca de doces) ou nas garagens das casas (quitanda, bar). Aprendemos a viver com bares espalhados por todas as cidades como se isso sempre tivesse existido. $\mathrm{O}$ fato chegou a tal ponto que nas periferias das grandes cidades a falta de opção de lazer transforma os bares em únicos locais de socialização para os homens, jovens, etc (Laranjeira \& Romano, 2003).

Como podemos observar, a média de dias e horas que esses estabelecimentos ficam abertos propicia ainda mais a facilidade do consumo. Com as portas abertas mais da metade do dia, o acesso aos bares é facilitado. A aglomeração de bares, restaurantes e lanchonetes em uma determinada região é um problema em si mesmo. Violência e acidentes de trânsito ocorrem com maior frequiência nesses locais (Babor et al., 2003). Na literatura internacional a situação considerada mais dramática foi observada na Finlândia em 1969, no período em que mercados e mercearias foram autorizados a vender cerveja com mais de 4,7\% de álcool, havendo maior facilidade para obtenção da licença para a abertura de restaurantes. Como resultado, houve um aumento de mercados e mercearias de 132 para 17600 , um aumento de bares e restaurantes de 940 para 4000 , o aumento global de álcool aumentou $46 \%$, as internações por psicose alcoólica aumentaram $110 \%$ entre os homens e $130 \%$ entre as mulheres, e as prisões por embriaguez aumentaram $80 \%$ entre os homens e $160 \%$ entre as mulheres (Saffer \& Grossman, 1987).

Assim, 1 estabelecimento para cada 2,6 casas, associado à facilidade do acesso devido à grande disponibilidade, baixo custo e falta de fiscalização efetivas pode implicar o aumento do consumo assim como dos problemas relacionados, no bairro escolhido para o estudo.

Assim, a implementação de um sistema de licenças para a venda do álcool poderia ser uma das políticas a ser empregadas neste bairro, mas tal estratégia ainda não abrange a complexidade presente naquela realidade. Junto com a inexistência de uma política de licença (que permite a qualquer pessoa abrir um estabelecimento e vender bebidas alcoólicas, como pode ser visto no bairro, onde a venda ocorre na rua, no carrinho de churrasquinho, na barraca de doces, na garagem de casas, em quitandas e bares) outras políticas públicas se fazem necessárias (educação, seguridade social, segurança pública, saúde, esporte, cultura, etc).

\section{Considerações Finais}

Assim, verificada a alta concentração de pontos de venda de bebidas alcoólicas encontradas no bairro (1 estabelecimento para cada 2,6 casas), podemos observar a facilidade do acesso às bebidas alcoólicas, o que poderá implicar aumento do consumo, assim como dos problemas relacionados. A necessidade de medidas políticas no município se faz presente, já que durante a abordagem aos comerciantes observamos a falta de legislação e/ou descumprimento, tornando a venda do álcool uma transação comercial qualquer, mesmo sendo este responsável por múltiplos problemas. Os dados existentes sobre os danos provocados pelo álcool no Brasil são suficientes para que se possa considerar essa condição própria em termos de saúde pública, merecendo, portanto, maior atenção governamental. 
O resultado deste estudo é de grande relevância, entretanto requer pensar que esta alta concentração de pontos de venda de bebidas alcoólicas se inscreve em um bairro inserido em uma região marcada por vários morros com ocupação urbana desordenada, índices preocupantes de tráfico de drogas e de trânsito de pessoas e carros que se dirigem às diferentes regiões da cidade de Vitória.

Está configurada a oportunidade para o desenvolvimento de políticas públicas em nosso município, visto que existem hoje produções que avaliam a eficácia das políticas públicas do álcool, fornecendo aos gestores indicadores que podem orientar a aplicação do dinheiro público considerando a relação custo/eficácia e abrangência das ações. No entanto, é fundamental pensar que a política para álcool, implementada hoje no mundo, requer entender também os múltiplos interesses envolvidos tais como: comerciais, da mídia, de grupos, da comunidade científica e do público em geral. É, portanto, um espaço de contradições e lutas que exige a invenção e reinvenção de formas de organização criativas e grupos de pressão que avancem com proposições e ações na área. No entanto, uma análise mais aprofundada nos permite entender que o cenário vislumbrado nesse bairro reflete os vários jogos presentes na arena política do álcool. Como outros produtos, o álcool é atrativo para a economia e requer atenção política para as formas de regulação, taxação e necessidades humanas, em virtude de seu potencial para gerar problemas (Babor et al., 2003). As ações na arena do álcool precisam ser conduzidas por sujeitos políticos que atendam aos interesses coletivos. Os gastos e problemas com o álcool podem ser minimizados a partir de medidas políticas comprovadas e sugeridas tanto por estudiosos quanto por organismos nacionais e internacionais (como a Organização Mundial de Saúde).

Babor et al. (2003) destacam que pensar políticas para o álcool, tais como as implementadas hoje no mundo, requer entender os múltiplos interesses envolvidos: comerciais, da mídia, de grupos, da comunidade científica e do público em geral. É, portanto, um espaço de contradições e lutas. A proposta de regulação sobre a cadeia produtiva (manufatura, distribuição, preço e venda) esbarra, por exemplo, nos interesses comerciais e no contexto neoliberal com ênfase no mercado.

No bairro estudado, foi apontado que a maior parte dos comerciantes e freqüentadores são moradores do próprio bairro; esse dado nos dá a entender que as pessoas que compõem a comunidade, e que poderiam unir-se a favor de interesses para a mudança da regulação da venda do álcool, têm interesses econômicos envolvidos com os locais onde comercializa bebida alcoólica (Laranjeira \& Hinkly, 2002). Mas, como apontado na revisão de literatura, as ações devem ser desenvolvidas na comunidade e pela comunidade, que deverá selecionar formas de organização criativas que avancem no enfrentamento das questões presentes nessa área.

\section{Notas}

Aqui também variará o conceito de "saudável".

2 Baseado em apresentação realizada por Tom Babor-Brasília, 2005.

3 Questão da auto-regulamentação do setor.

4 O objetivo foi levantar informações sobre as características da comercialização de bebidas alcoólicas no bairro considerando a diversidade de comércios presentes.

5 O formulário foi utilizado com autorização prévia dos autores, e contém 47 itens que foram aplicados aos proprietários dos bares ou, em sua ausência, ao responsável no momento. Esse instrumento foi desenvolvido com a finalidade de avaliar a densidade e características de pontos de venda de álcool na região de Jardim Ângela (São Paulo).

\section{Referências}

ANVISA (2005). Anvisa defende controle da propaganda em prol da saúde. Retrieved on 29/12/2005 from www.anvisa.gov.br/ divulga

Associação Brasileira dos Departamentos de Trânsito (1997). Impacto do uso do álcool e outras vítimas de acidentes de trânsito. Brasília: CETAD/RAID, 1997.

Babor, T. F., Caetano, R., Casswell, S. et al. (2003). Alcohol: ordinary commodity. Oxford: Oxford Press.

Baioco, M. (1999). Concepções sobre alcoolismo entre estudantes de áreas de conhecimento distintas em uma universidade pública. Dissertação de Mestrado não-publicada, Programa de PósGraduação em Psicologia, Universidade Federal do Espírito Santo. Vitória, ES.

Bertolote, J. M. (1997). Problemas sociais relacionados ao consumo de bebidas. In S. P. Ramos \& J. M. Bertolote (Eds.), Alcoolismo hoje (pp. 131-138). Porto Alegre: ArtMed.

Brasil - Secretaria Nacional Antidrogas (2003). Drogas e Violência. Retrieved on 04/12/2003 from www.senad.gov.br

Ceará-Departamento de trânsito (2003). Álcool e direção. Retrieved on 19/09/2003 from www.detran.ce.gov.br

Chaloupka, F., Groffman, M. \& Saffer, H. (2002). The effects of price on alcohol consumption and alcohol-related problems. Alcohol Research and Heath, 26, 22-34.

Edwards, G. (1994). A política do álcool e o bem comum. São Paulo: ArtMed.

Espírito Santo - Secretaria Estadual de Saúde (2004). Internação ES por CID: 2004 jan a mar. Vitória: SES.

Gomes, M. P. Z. (1990). Complicações clínicas do alcoolismo. In Consultre (Ed.), Alcoolismo (pp. 5-13). Vitória: Consultre.

Holder, H. D. (1997). Alcohol use and a safe environment. Addiction, 92, S117-S120.

Holder, H. D. (2001). Prevention of alcohol problems in the $21{ }^{\text {st }}$ Century: challengs and opportunities. The American Journal on Addiction, 66, 9-11.

Laranjeira, R. \& Hislky, D. (2002). Evaluation of alcohol outlet density and characteristics in a poor area of São Paulo: in search of an alcohol policy for the city. São Paulo: Universidade Federal de São Paulo.

Laranjeira, R. \& Romano, M. (2003). Políticas públicas para o álcool. São Paulo: Universidade Federal de São Paulo, Programa de pesquisas em políticas públicas. 
Basílio, M.C.V.; Garcia, M.L.T. "Vendas de bebidas alcóolicas: questões (im)pertinentes"

Laranjeira, R. (2004). Racionalização de drogas no Brasil: em busca da racionalidade perdida. Retrieved on 12/02/2004 from www. abead.com.br/asp/políticcas.asp

Leite, F. (2004). Governo não conclui projeto sobre álcool. Retrieved on 05/04/2004 from www1.folha.uol.com.br/fsp/cotidian

Oliveira, E. M. \& Melcop, A. G. (1997). Álcool e trânsito. Recife: Instituto RAID/ COFEN/DETRAN-PE.

Paschoal, J. (2005). A importância do encontro sobre drogas: aspectos penais e criminológicos. In Miguel Reale Júnio (Org.), Drogas: aspectos penais e criminológicos (pp. 1-8). Rio de Janeiro: Forense.

Pinsky, I. (1994). Análise da propaganda de bebidas alcoólicas na televisão brasileira. Dissertação de Mestrado não-publicada, Programa de Pós-graduação em Psicologia, Universidade Federal de São Paulo. São Paulo, SP.

Pinsky, I. (1999). O comportamento de dirigir alcoolizado entre jovens de São Paulo: Perfil de Risco. Tese de Doutorado nãopublicada, Programa de Pós-Graduação em Psiquiatria, Escola Paulista de Medicina, Universidade Federal de São Paulo. São Paulo, SP.

Pinsky, I. (2004). A propaganda de bebidas alcoólicas no Brasil. Retrieved on 12/06/2004 from www.propagandasembebida.org.br/ artigos/integra.php?id=12

Rua. M. G. (s/d). Análise de Políticas Públicas: conceitos básicos. UnB, [mimeo], 19p.

Saffer, H. \& Grossman, M. (1987). Driking age laws and highway mortality rates: cause and effect. Economic Inquire, 16, 351-374.

Silva, I. F. (2000). O processo decisório nas instâncias colegiadas do SUS no estado do Rio de Janeiro. Dissertação de Mestrado não-publicada, Escola Nacional de Saúde Pública, Fundação Oswaldo Cruz. Rio de Janeiro, RJ.

United States (1996). National Institute on Alcohol Abuse and Alcoholism. Alcohol research and social policy. Retrieved on 04/12/2003 from www.niaaa.nih.gov/publications/iss20-4.htm

Viana, A. L. D. (1996). Enfoques metodológicos em políticas públicas: novos referenciais para os estudos sobre as políticas sociais. In V. Lemieux et al. (Orgs), Lê Systeme ao Quebec Organisations. Acteurs et Enjeux Sainte Foy (pp. 205-215). Laval: Lês Presses.
Vitória - Secretaria de Desenvolvimento da Cidade (2003). Estatísticas de acidentes de trânsito em Vitória: localização dos acidentes. Vitória: SDC.

Vitória - Departamento da Polícia Militar da Vila Rubim (2004). Relatos de ocorrências relacionadas ao abuso do álcool. (Entrevista concedida a Mirian Cátia Vieira Basílio, Vitória, 16/07/2004).

World Health Organization (1995). A summary of alcohol policy and the public good: a guide for action. Retrieved on 14/02/1995 from www.who.int/en/

Mirian Cátia Vieira Basílio. Assistente Social formada pela Universidade Federal do Espírito Santo, aluna do Mestrado em Política Social/UFES. mirianbasilio@yahoo.com.br

Maria Lúcia Teixeira Garcia. Professor Adjunto III do Departamento de Serviço Social do Centro de Ciências Jurídicas e Econômicas da Universidade Federal do Espírito Santo, membro do NEAD-CBMUFES, pesquisadora CNPq, coordenadora do Mestrado em Política Social/UFES, coordenadora da Pesquisa Política de Atenção à dependência Química em Vitória (FACITEC). lucia-garcia@uol.com.br

\section{Vendas de bebidas alcóolicas: questões (im)pertinentes}

Mirian Cátia Vieira Basílio e Maria Lúcia Teixeira Garcia

Recebido: 13/10/2005

$1^{\text {a }}$ revisão: 25/01/2006

$2^{\mathrm{a}}$ revisão: $18 / 05 / 2006$

$3^{\mathrm{a}}$ revisão: $21 / 08 / 2006$

Aceite final: 31/08/2006 